\title{
Surgical Correction and Osteoplasty for Forward Dislocation of Temporomandibular Joint
}

\author{
Keigo KUDO, Masaru SHOJI, Kazushige YAMAGUCHI, \\ Mitsumasa YOKOTA and Yukio FUJIOKA
}

(Received 19 July and accepted 24 July 1989)

Key words: bone graft, down-fracture of zygomatic arch, forward dislocation of TMJ, recurrent dislocation of TMJ

\begin{abstract}
Surgical correction and osteoplasty were carried out in one case of prolonged and three cases of recurrent forward dislocation of the temporomandibular joint, two of the patients in the latter cases having mental disorders and one having a cerebral lesion. A hockey-stick-shaped preauricular incision was made, ending in the hair-bearing part of the temple. Then, the temporal fascia and muscle were divided anteriorly from the temporal bone. In two aged patients, a fragment of the zygomatic arch was pushed out and down, joining under the articular tubercle. In two younger patients, the cortical bone of the mandible was separated by sagittal split-ramus osteotomy for mandibular prognathism, and two graft blocks removed from the iliac bone were implanted between the root of the posterior zygomatic arch and the anterior cut-edge of the articular tubercle. In 3 of the 4 patients, the fragments or grafts were fixed by means of ligation using wire so as to make contact with the root of the posterior zygomatic arch. There was no recurrence of dislocation during a period of 2-5 years after surgery.
\end{abstract}

\section{Introduction}

For forward dislocation of the temporomandibular joint, manual repositioning is used in the ordinary way. However, in cases of prolonged or recurrent forward dislocation, surgical correction ${ }^{[1,2]}$ or osteoplasty ${ }^{[3]}$, which increases the height of the articular tubercle to prevent the recurrence of dislocation, is reported to be more useful. However, in some patients treated by these surgical techniques, the moved zygomatic fragment or bone graft is somewhat unstable. In this paper we report the results of intraosseous ligation using wire to obtain a more rigid fixation.

\section{Materials and Methods}

\section{Patients with Forward Dislocation}

Four patients, one with prolonged and three with recurrent forward dislocation of the temporomandibular joint, were referred to the Dental Clinic of Iwate Medical University between 1984 and 1987. In patient 1, a 70-year-old man, left 工藤啓吾, 東海林克, 山口一成, 横田光正, 藤岡幸雄：Department of Oral and Maxillofacial Surgery, School of Dentistry, Iwate Medical University, 1-3-27 Chuodori, Morioka, Iwate 020, JAPAN. 
prolonged and locked dislocation occurred following a fracture of the maxilla and zygoma 3 months previously and was manifested as a shifted occlusion of the patient's full dentures. The cases of recurrent dislocation were associated with spasmodic movement of the mandible and edentulous jaws without dentures, after surgery for cerebral aneurysm in a 73-year-old woman (patient 2) and prognathism in a 22-year-old schizophrenic woman (patient 3), and a 29-year-old woman with mental deficiency (patient 4), respectively (Table 1). In two patients (patients 3 and 4), the first dislocations were due to opening of the mouth during dental treatment, followed by subsequent recurrences.

Table 1 Descriptions of patients with schematic illustrations of surgical techniques employed.

\begin{tabular}{|c|c|c|c|c|c|}
\hline \multirow{2}{*}{ Patient } & Sex & Diagnosis & \multirow{2}{*}{$\begin{array}{l}\text { Surgical correction } \\
\text { and osteoplasty }\end{array}$} & $\begin{array}{l}\text { Mandibular } \\
\text { fixation }\end{array}$ & \multirow{2}{*}{ Follow-up } \\
\hline & Age & Complication & & $\begin{array}{l}\text { Range of mouth } \\
\text { opening }\end{array}$ & \\
\hline 1 & $\begin{array}{l}M \\
70\end{array}$ & $\begin{array}{l}\text { Prolonged dis- } \\
\text { location of left } \\
\text { condyle }\end{array}$ & $\begin{array}{l}\text { Vertical down- } \\
\text { fracture }\end{array}$ & $\begin{array}{l}\text { Using bandage } \\
45 \mathrm{~mm}\end{array}$ & $\begin{array}{l}\text { No recurrence } \\
\text { for } 5 \text { years }\end{array}$ \\
\hline 2 & $\begin{array}{l}\mathrm{F} \\
73\end{array}$ & $\begin{array}{l}\text { Recurrent dis- } \\
\text { location of } \\
\text { bilateral con- } \\
\text { dyle } \\
\text { Amputation of } \\
\text { left leg due to } \\
\text { arterial throm- } \\
\text { bosis and cere- } \\
\text { bral aneurysm }\end{array}$ & $\begin{array}{l}\text { Oblique down- } \\
\text { fracture }\end{array}$ & $\begin{array}{l}\text { None } \\
40 \mathrm{~mm}\end{array}$ & $\begin{array}{l}\text { No recurrence } \\
\text { for } 2 \text { years }\end{array}$ \\
\hline 3 & $\begin{array}{l}F \\
22\end{array}$ & $\begin{array}{l}\text { Recurrent dis- } \\
\text { location of } \\
\text { bilateral con- } \\
\text { dyle } \\
\text { Sagittal split- } \\
\text { ramus osteotomy } \\
\text { for mandibular } \\
\text { prognathism; } \\
\text { schizophrenia }\end{array}$ & $\begin{array}{l}\text { Mandibular cortical } \\
\text { bone grafting }\end{array}$ & $\begin{array}{l}\text { With bite splint } \\
40 \mathrm{~mm}\end{array}$ & $\begin{array}{l}\text { No recurrence } \\
\text { for } 3 \text { years } \\
\text { Slight resorp- } \\
\text { tion of graft }\end{array}$ \\
\hline 4 & $\begin{array}{l}F \\
29\end{array}$ & $\begin{array}{l}\text { Recurrent dis- } \\
\text { location of } \\
\text { bilateral con- } \\
\text { dyle } \\
\text { Mental deficiency }\end{array}$ & Iliac bone grafting & $\begin{array}{l}\text { Use of chin cap } \\
32 \mathrm{~mm}\end{array}$ & $\begin{array}{l}\text { No recurrence } \\
\text { for } 2 \text { years } \\
\text { Slight resorp- } \\
\text { tion of graft }\end{array}$ \\
\hline
\end{tabular}




\section{Surgical Techniques}

Skin incision: Under general anesthesia, a skin incision in the shape of a hockey-stick was made from the preauricular region to the hair-bearing part of the temple. The skin flap divided on the temporal muscle and fascia was elevated anteriorly and posteriorly. Then, the periosteum, for a length of $1-1.5 \mathrm{~cm}$ anteriorly toward the zygomatic arch from the articular tubercle, was horizontally divided, and the surgical field was adequately exposed.

Down-fracture of the zygomatic arch: In the two aged patients, the zygomatic arch on the articular tubercle was cut vertically (patient 1) (Fig. 1-A) or obliquely
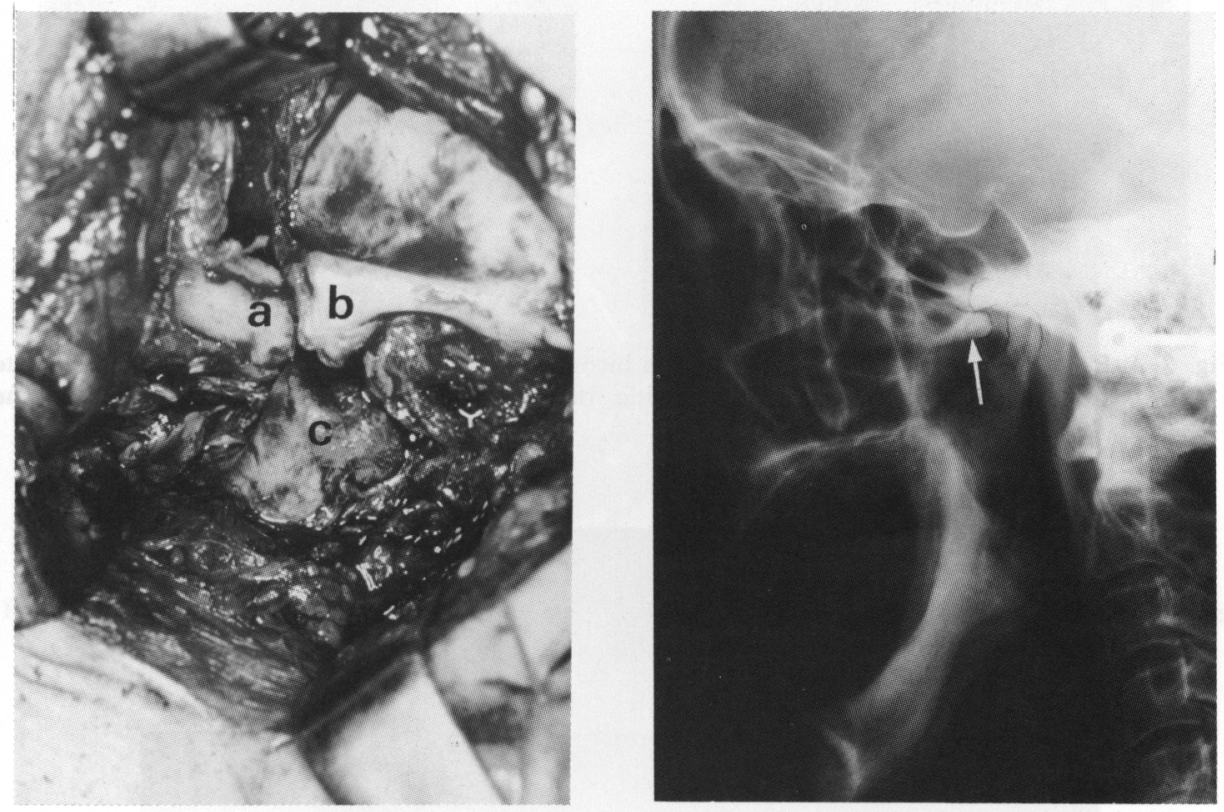

Fig. 1-A Zygomatic fragment (a) inferiorly moving after vertical cut of the articular tubercle (b) and condyle (c) partially resorbed due to prolonged fracture in patient 1 .

Fig. 1-B Postoperative X-ray photograph of the zygomatic fragment (arrow) located under the articular tubercle and condyle in patient 1 .

(patient 2) using a fissure burr or a bone saw. Afterwards, using a nasoseptal chisel, the arch was patted to the outside with a hammer, and then pushed down inferiorly (Fig. 2-A, B). The zygomatic fragmens of patient 2, which brought the incomplete (right side) or complete (left side) fractures to the site of zygomatico-malar suture, were placed under the tubercle. However, intraosseous ligation at the bilateral edges, using $0.4-\mathrm{mm}$ wire for the somewhat unstable fragments, especially those caused by complete fracture, was performed (patient 2). Only a chinbandage was used for 14 days in patient 1 (Table 1).

Bone grafting: In the two younger patients, a piece of cortical bone measuring 

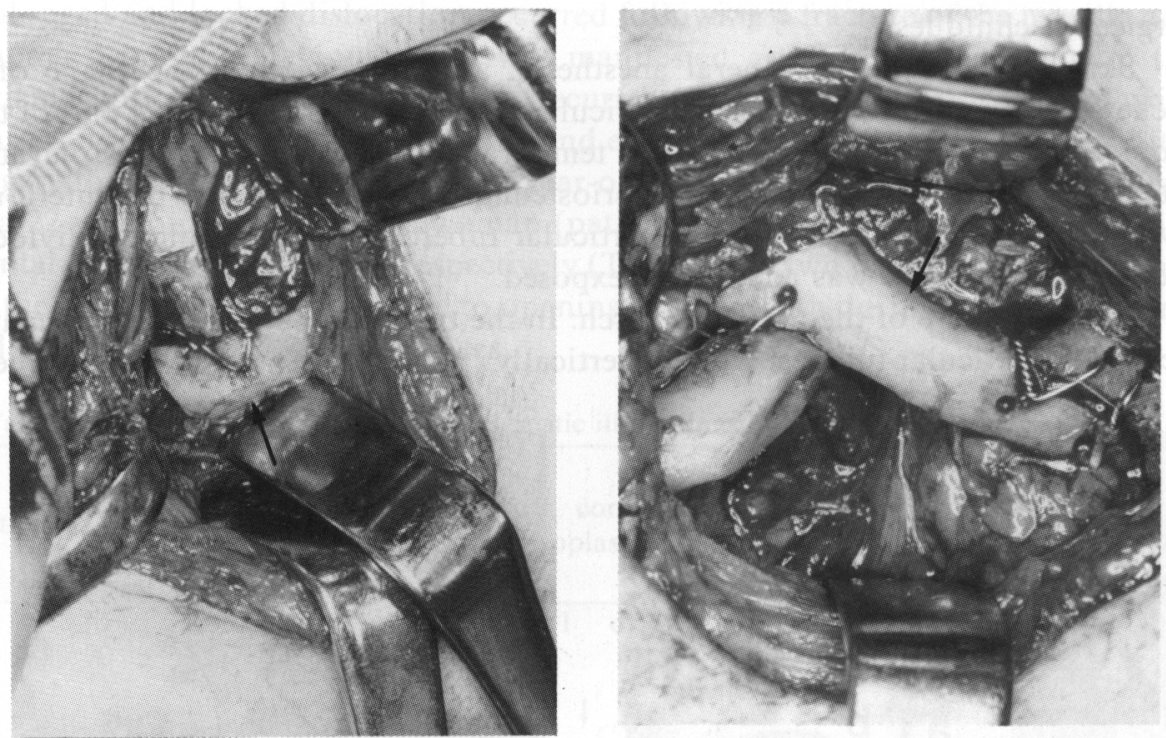

Fig. 2-A, B Wire-fixation of the right side with incomplete (A, left), or of the left side with complete (B, right) fractures of the zygomatic fragments (arrows), which have moved under the articular tubercle in patient 2 .

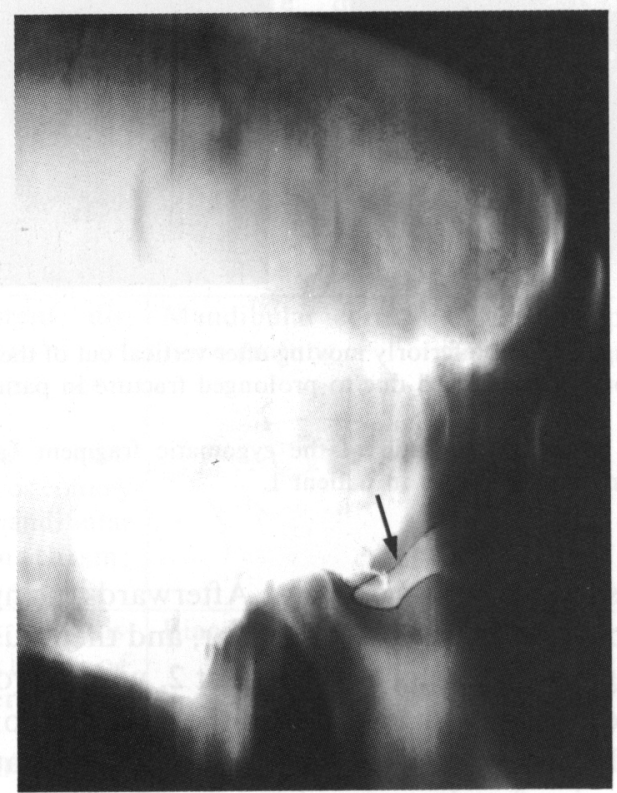

Fig. 2-C Postoperative $\mathrm{X}$-ray photograph of the right zygomatic fragment (arrow) with wire-fixation in patient 2 . 
about $4 \times 1.5 \mathrm{~cm}$, excised upon sagittal split-ramus osteotomy on the right side for mandibular prognathism (patient 3), and two bone blocks measuring about $4 \times 2$ $\mathrm{cm}$, removed from the iliac bone without the crest (patient 4 ), were implanted so as to fit the cut surface into the root of the zygomatic process of the temporal bone either uni- or bilaterally. Subsequently, intraosseous or letter-x ligation for the zygomatic arch and the graft was performed in order to make their fixation rigid (Figs. 3-A, 4-A). Efficient mouth-opening by the patients was confirmed before

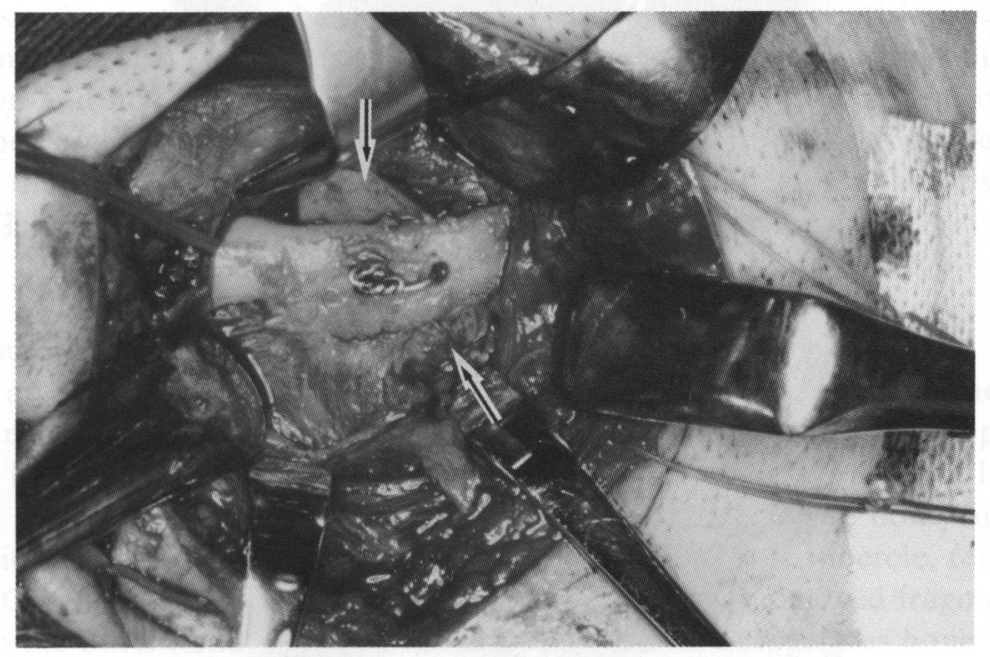

Fig. 3-A Implantation (arrows) with wire-fixation to the root of the zygomatic arch of a cortical bone piece cut by sagittal split-ramus osteotomy of the mandible in patient 3 .

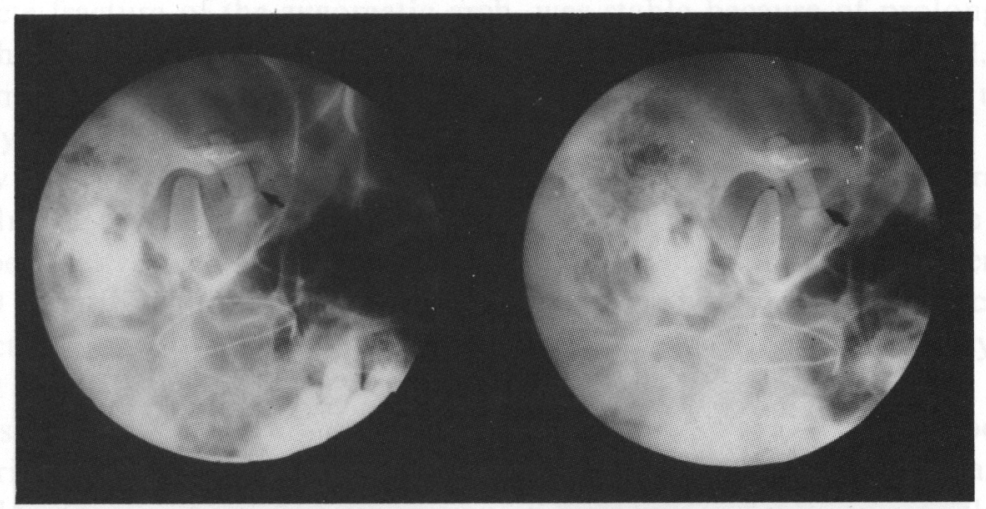

Fig. 3-B Postoperative X-ray photograph after implantation (arrows) of the cortical bone piece in patient 3 , with the mouth closed (right side) and open(left side). 


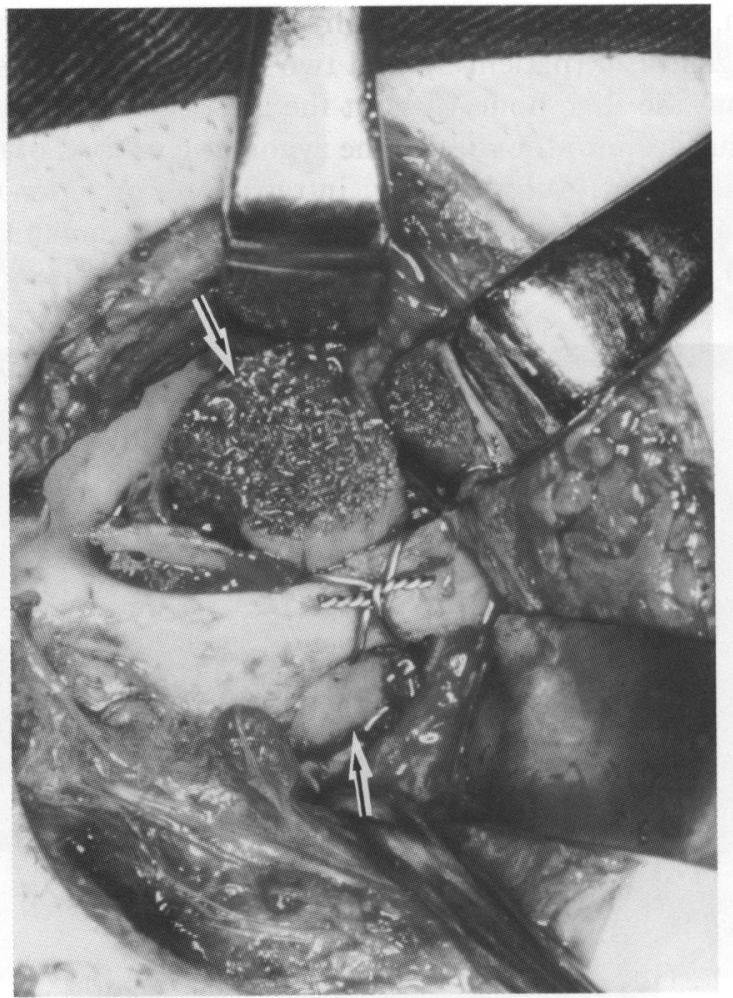

Fig. 4-A Implantation (arrows) of an iliac bone block with wire-fixation between the temporal squamous part and the root of the zygomatic arch in patient 4.

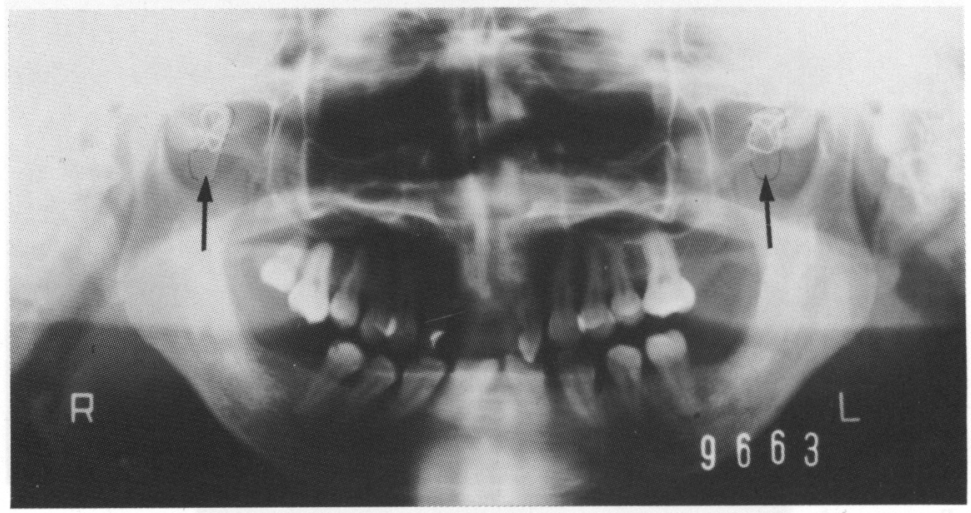

Fig. 4-B Postoperative panoramic X-ray photograph after implantation of the iliac bone (arrows) in patient 4 . 
ligation following the bone grafts. Finally, a wound-suction tube was held in place for 2-3 days, then the skin flap was replaced and sutured. Intermaxillomandibular (patient 3) or mandibular (patient 4) fixation for 4 or 2 weeks was done postoperatively (Table 1). There were no postoperative infections or complications.

\section{Results}

In a period of 2-5 years after surgery, there was no restriction of mouthopening in 3 of the 4 patients. However, only one patient (patient 4) with osteoplasty due to the iliac bone graft had slightly restricted mouth-opening of 33 $\mathrm{mm}$ even at 2 years after surgery, in spite of a gradual improvement of this restriction and no other problems in daily life. Although slight resorption of the grafted bone was observed on X-ray photographs, no recurrence of dislocation or palsy of the facial nerve was seen in any of the patients within the observation period (Table 1, Figs. 1-B, 2-C, 3-B, 4-B).

\section{Discussion}

A surgical procedure for increasing the height of the articular tubercle through a vertical cut, incomplete fracture of the zygoma and inferior and medial lock for recurrent dislocation of the temporomandibular joint was first reported in 1943 by LECLERC and GIRARD ${ }^{[1]}$. However, there was a problem of holding the removed zygomatic fragment. Later, an anteroinferiorly oblique bone cut for the zygomatic arch to the right at a site anterior to the articular tubercle, reported in 1967 by Gosserez and DAUTREY ${ }^{[2]}$, made the fixation of the moved fragment more rigid. On the other hand, a piece of kiel bone ${ }^{[4]}$ and an autogenous bone ${ }^{[5]}$ grafted onto the fragment, or a bone block ${ }^{[3]}$ wedged and implanted in the root of the articular tubercle, have been used in order to prevent repositioning of the fragment. The fragment in patient 1 , which moved through the vertical bone cut and incomplete fracture of the zygomatic arch, was stable because of prolonged fracture at the zygomatico-malar suture. However, the fragment in patient 2 , in spite of movement through the oblique bone cut, the fragment was somewhat unstable, especially since it became free due to the complete fracture on the right side and probably did not result in bone union, necessitating fixation with intraosseous wiring. In this respect, Gosserez and DAUTREY ${ }^{[2]}$ described that a true fracture should be avoided because of elasticity of the arch until an average patient age of about 40 years. For the two aged patients described above, surgical correction was less effective and the usage of intraosseous ligation for the fractured zygomatic fragment was indicated.

SPISSEL and TSCHOP $^{[3]}$ described that fixation achieved by wedging a bone graft with a triangular cut between the zygomatic arch and the squamous part of the temporal bone at the root of the articular tubercle was unnecessary. However, forward dislocation of the temporomandibular joint due to an unstable bone graft might have proved to be recurrent, since the size or thickness of the graft was insufficient, especially in patient 3 in whom cortical bone from the mandible was used. Therefore, ligation using wire was performed for the two patients with bone graft. No information concerning recurrent dislocation due to resorption of a bone 
graft after osteoplasty could be found in our search of the literature. Even if slight resorption of a bone graft like that in patients 3 and 4 were to continue in the future, prevention of recurrent dislocation due to muscular recovery could be expected. It is considered that the longer bone graft used in patient 4 caused slight disturbance of mouth-opening.

The etiology of recurrent dislocation of the temporomandibular joint is unclear. However, patients with mental disorders, cerebral lesions and those under medication with phenothiazine ${ }^{[6]}$ may tend to bring on recurrent dislocation through movement of involuntary muscles and malocclusion.

\section{Conclusion}

If the zygomatic fragments or implanted bone grafts used for increasing the height of the articular tubercle are unstable, wire-fixation to make these more rigid should be performed. We showed in this study that surgical correction or osteoplasty of the zygomatic fragment by intraosseous wiring-fixation was able to provide extended relief in aged patients.

\section{References}

[1] $\mathrm{L}_{\mathrm{E}} \mathrm{C}_{\mathrm{LeRC}}, \mathrm{G}$. and Girard, G.: Un nouveau procédé de butée dans le traitement chirugical de la luxation récedivante de la mâchoire inférieure, Mém. Acad. Chir., 69, 451-459, 1943

[2] Gosserez, M. and Dautrey, J.: Osteoplastic bearing for the treatment of temporomandibular luxation, Oral surgery, Transactions, 2nd Congress of the International Association of Oral Surgeons, Husted, E., Munksgaad, Copenhagen, 261-264, 1967

[3] Sissel, B. and Tschop, H. M.: Osteoplasty for habitual subluxation of the temporomandibular joint, In: Head and Neck Surgery, 253-356, Nauman, H. H., Ed., Thiem, Stuttgart, 1980

[4] SCHULE, H.: Untersuchungen zur Bewertung konservativer und chirurgischer Massnahmen bei Kiefergegensdysfunktion, Dtsch. Zahnärztl. Z. 27, 826-830, 1972

[5] Oka, T., T amaki, H., K aneda, T., OKoshi, M., S AKai, K., Shibata, S., Kotani, J. and NAGAYAma, M.: Surgical approach for habitual forward subluxation of the temporomandibular joint, J. Jp. Stomatol. Soc., 23, 539-546, 1974 (in Japanese)

[6] MILLER, G. A. and Murphy, E. G.: External pterygoid myotomy for recurrent mandibular dislocation, Oral Surg., 42, 705-714, 1976 